\title{
Analgesic Outcomes of Tramadol Alone and in Combination with Butorphanol or Flurbiprofen Axetil after Caesarean Section: A Retrospective Study with Propensity Score Matching Analysis
}

\author{
Guiying Yang \\ Second Affiliated Hospital of Army Medical University \\ Zhuoxi Wu \\ Second Affiliated Hospital of Army Medical University \\ Qiangting Deng

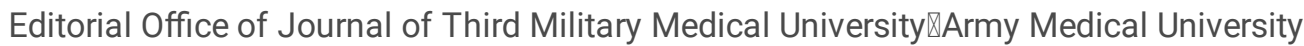 \\ Yan liang \\ Second Affiliated Hospital of Army Medical University \\ Xiaohang Bao \\ Second Affiliated Hospital of Army Medical University \\ Guangming Yan \\ Second Affiliated Hospital of Army Medical University \\ Jing Peng \\ Second Affiliated Hospital of Army Medical University \\ Wenjun Liu \\ Second Affiliated Hospital of Army Medical University \\ Dan Tan \\ Second Affiliated Hospital of Army Medical University \\ Hong Li ( $\square$ lh78553@163.com ) \\ Second Affiliated Hospital of Army Medical University
}

\section{Research Article}

Keywords: Caesarean section, Analgesia, Tramadol, Flurbiprofen axetil, Butorphanol

Posted Date: October 28th, 2021

DOI: https://doi.org/10.21203/rs.3.rs-957104/v1

License: (c) (i) This work is licensed under a Creative Commons Attribution 4.0 International License. Read Full License 


\section{Abstract}

Background: To our knowledge, the Society for Obstetric Anesthesia and Perinatology recommends a multimodal analgesic regimen for caesarean delivery analgesia. Therefore, this study aimed to compare the analgesic effects of tramadol alone and in combination with butorphanol or flurbiprofen axetil after caesarean section.

Methods: We retrospectively analysed 2323 women with puerperas who had undergone caesarean section based on the electronic medical records of a teaching hospital in China from January 2018 to January 2020. We collected data on demographic characteristics, perioperative complications, surgical factors, and anaesthesia. We also recorded the postoperative analgesic solution, pain intensity (assessed by the numeric rating scale [NRS]) during the first 48 hours after surgery. Postoperative inadequate analgesia during the postoperative 48 hours was defined as an NRS score $\geq 4$. We also collected data regarding off-bed activity and intestinal function recovery. Analgesic outcomes of three groups were compared using propensity score matching analysis.

Results: Compared to the tramadol mixed with butorphanol group (group B), the incidence of inadequate analgesia at rest and while moving was lower in the tramadol combined with flurbiprofen axetil group (group F), and the relative risks (RRs) for women with puerperas suffering from inadequate analgesia at rest and while moving in group $\mathrm{F}$ were 0.34 (95\% confidence interval [Cl]: $0.21-0.54 ; P<0.001)$ and 0.24 (95\% $\mathrm{Cl}: 0.19-0.31, P<0.001)$, respectively. The percentage of intestinal function recovery and offbed activity at 2 days postoperatively was higher in group $B$ than in group $F(74.1$ versus [vs.] $66.4, P=0.006$ and $79.4 \%$ vs. $66.4 \%$, $P<0.001$, respectively). Group $\mathrm{F}$ was also associated with a lower incidence of inadequate control of pain at rest and while moving than group $T(R R, 0.37$ [0.23-0.60], $P<0.001$, and 0.43 [0.33-0.55], $P<0.001$, respectively). Group $B$ was associated with a higher incidence of inadequate control of moving pain than group T (RR, 1.78, [1.40-2.26], $P<0.001)$.

Conclusions: A combination of tramadol and flurbiprofen axetil could enhance the analgesic effect and be safely used for analgesia after caesarean section, but the combination of tramadol and butorphanol may produce an antagonistic effect.

Trial registration: Not applicable.

\section{Background}

Caesarean section is the most common surgery globally. Inadequate analgesia after caesarean section is common,[1,2] and the average numeric rating scale (NRS) score is more than 6 on day 1 postoperative.[3] Therefore, study of the analgesic strategy after caesarean section is very important. Neuraxial analgesia provides optimal pain relief after caesarean section through patient-controlled epidural analgesia (PCEA).[4] However, epidural catheter dislocation[5] or slippage[6] and the infection risk[7] limit the clinical application of PCEA. Patient-controlled intravenous analgesia (PCIA) offers another pain control method after caesarean section without those complications. However, in the Practice Bulletin of Obstetric Analgesia and Anaesthesia 2019 , no optimal strategy of intravenous analgesia was recommended for pain treatment in women after caesarean section.[8]

Tramadol is a commonly used analgesic after caesarean section[9]. Women with caesarean section are at a high risk for postpartum depression, and our preliminary studies suggested that PCIA with tramadol could alleviate anxiety and depression in the early postpartum period[10,11]. Thus, we choose to use it as the main analgesic drug after caesarean section, but tramadol has no obvious analgesic effect on visceral pain.

Women who have had a caesarean section have both incision and visceral pain, because oxytocin is routinely used in clinical practice to reduce uterine bleeding after caesarean section, and uterine cramping pain (UCP) is induced at the same time. Butorphanol is both a kappa-agonist and a mu-antagonist analgesic, and is associated with less respiratory depression in an equianalgesic dose. Hence, butorphanol provides optimal visceral pain relief after caesarean sections. It is safe for women who are breastfeeding in the early post-partum period, which is why it is widely used as analgesia after caesarean section. $[12,13]$ Therefore, we thought that the combination of tramadol with other analgesic drugs that have an analgesic effect on visceral pain may be a good choice for women with caesarean section. 
Current studies have suggested that non-steroidal drugs have a good effect on UCP.[14] Flurbiprofen axetil is a non-selective nonsteroidal drug, and it is safe for women who are breastfeeding in the early post-partum period[15囚16]; thus, it is also safe for caesarean section analgesia.

To our knowledge, the Society for Obstetric Anaesthesia and Perinatology recommends a multimodal analgesic regimen for caesarean delivery analgesia. It is beneficial for patients to choose a combination of analgesics that is effective and safe for both the mother and the newborn. Therefore, we conducted a retrospective study on the postoperative analgesia effects of tramadol alone and in combination with flurbiprofen axetil or butorphanol after caesarean section and conducted propensity score matching (PSM) analysis to explore the differences in postoperative analgesia effects among the drug combinations.

\section{Methods}

\section{Study Design and Patients}

This single-centre retrospective cohort study investigated the postoperative analgesia effects of tramadol alone and in combination with flurbiprofen axetil or butorphanol after caesarean section. This study protocol was approved by the Institutional Ethics Committee of the Second Affiliated Hospital of Army Medical University, Chongqing, China (approval ID: 2020101-01). Written informed consent was not required from all the participants.

The inclusion criteria were women with a gestational age of 37-40 weeks, an American Society of Anaesthesiology physical status of I-II, and singleton pregnancy. The exclusion criteria were women having a multiparous pregnancy, receiving epidural or general anaesthesia, and having missing data. As shown in Figure 1, from January 2018 to January 2020, we enrolled a total of 2323 Chinese women aged 20-44 years who had undergone caesarean section under subarachnoid space block anaesthesia.

\section{Patient Data and Outcomes Collection}

\section{Data source}

All data were based on the electronic medical records of The Affiliated Hospital of Army Medical University from January 2018 to January 2020. A gynaecologist recorded baseline data and preoperative demographics. Anaesthesia-related data and intraoperative complications were recorded by an anaesthetist. Postoperative follow-up was performed by a nurse anaesthetist.

\section{Analgesia and Anaesthesia}

Anaesthesia was administered by an experienced anaesthesiologist. Spinal anaesthesia was used for all the patients, and ropivacaine (AstraZeneca AB; 18-22 mg) was administered at the puncture site (L2-L3 or L3-L4 level). Postoperative analgesia was started immediately after caesarean section. PCIA was performed through a mechanical infusion pump. Three analgesic strategies were selected, and patients were classified into three groups according to those analgesic regimens. The tramadol group (group T) received a mixture of tramadol (Sandoz [China] Pharmaceutical Co., Ltd.; $800 \mathrm{mg}$ ) with $0.9 \%$ normal saline at a dose volume of $200 \mathrm{~mL}$, flurbiprofen axetil group (group F) received a mixture of tramadol $(800 \mathrm{mg}$ ) and flurbiprofen axetil (Teide Pharmaceutical Co., Ltd., Beijing, China; $200 \mathrm{mg}$ ) with $0.9 \%$ normal saline at a dose volume of $200 \mathrm{~mL}$, and butorphanol group (group B) received a combination of tramadol $(800 \mathrm{mg}$ ) and butorphanol (Hengrui Pharmaceutical Co., Ltd., Jiangsu, China; $2 \mathrm{mg}$ ) with $0.9 \%$ normal saline at a dose volume of $200 \mathrm{~mL}$ for PCIA. The PCIA pump was designed to have a background infusion rate at $4.0 \mathrm{~mL} / \mathrm{h}$, and an additional dose of $1 \mathrm{~mL}$ with a lockout period of $15 \mathrm{~min}$.

\section{Outcomes}


Postoperative pain intensity was evaluated using the NRS (score, $0-10$ ), where 0 is defined as no pain and 10 as maximum pain, at $6,12,24$, and 48 hours. The incidence of postoperative inadequate analgesia during the first 48 hours after caesarean section was the primary outcome because it is considered as an important basis for the use of supplementary analgesia in clinical practice. Inadequate analgesia was defined as an NRS score $\geq 4$ during the postoperative 48 hours. In addition, the number of patients who requested an extra rescue pain treatment during the postoperative analgesia was recorded.

We also recorded the following maternal preoperative complications for all the included women:

- Gestational diabetes mellitus, including previously diagnosed diabetes and emerging diabetes during the gestational period;

- Gestational hypertension, which included pre-pregnancy hypertension, emerging hypertension during pregnancy, preeclampsia, or eclampsia;

- Oligoamnios and polyhydramnios, which is defined as amniotic fluid volumes $<300 \mathrm{~mL}$ and $>2000 \mathrm{~mL}$, respectively, during pregnancy;

- Placental diseases including placenta previa and placenta abruption;

- Foetal macrosomia, which is defined as a foetus weighing $\geq 4000 \mathrm{~g}$;

- Pre-diagnosed foetal diseases including foetal congenital brain disease, heart disease, and kidney disease, such as hydrocephalus and hydronephrosis, etc.;

- Premature membrane rupture, which refers to membrane rupture before regular uterine contractions;

- Synchronised surgery, which included women who underwent other surgeries during the caesarean section, such as simultaneous ligation, ovarian cyst surgery, uterine fibroid surgery, etc.

Demographic data such as age and body mass index (BMI), as well as data on intraoperative blood loss volumes, were collected. Additionally, we recorded patients in whom intrauterine balloon tamponade was used for uterine inertia and postpartum haemorrhage treatment. Moreover, postoperative off-bed activity and intestinal function recovery at 2 days after surgery, length of hospitalisation stay, and the hospitalisation cost were recorded.

\section{Statistical Analysis}

Continuous variables are presented as mean \pm standard deviation (SD), while number (frequency) is used to summarise categorical variables. A stepwise logistic regression analysis was performed, and all baseline variables were included in this model. Furthermore, the relative risks (RRs) values for the occurrence of inadequate analgesia during the postoperative 48h was calculated with a $95 \%$ confidence interval $(\mathrm{Cl})$.

All groups were matched by propensity scores, and all factors performed to generate the propensity scores were those perioperative factors that showed significant differences between every two groups, or have been reported in previous study to have an effect on pain. The packages 'foreign', 'dplyr', 'RMS', and 'VIM' in R language (version 3.0.1; http://www.Rproject.org) were used to perform PSM between three groups for statistical analysis. Matching was carried out using the 1:1:1 nearest method, and 0.2 was set as the calliper value. The propensity score was calculated for the following baseline variables: age, BMI, duration of operation, placenta disease (yes/no), intraoperative blood loss, gestational diabetes (yes/no), other synchronised surgery (yes/no), and primiparas or multiparas. Finally, 553 patients were matched in each group. Between each of the two groups, normal-distributed continuous data were compared using the Student's t-test, while the differences among the abnormally distributed continuous parameters were compared using the Mann-Whitney U test. Additionally, categorical variables were compared using the chi-square test or Fisher exact test. The P-value were corrected by Bonferroni correction. All data were analysed using SPSS 26.0 (IBM Corp.) and R software (version 3.0.1; http://www.Rproject.org). A two-sided P-value $<0.05$ was considered to be statistically significant.

\section{Results}

\section{Risk Factor Analysis}


We enrolled 2323 patients: 1058 in group F, 601 in group B, and 664 in group T. As summarised in Table 1, for all included maternal women, the results of stepwise logistic regression analysis showed that placenta disease and the length of operative time were risk factors of inadequate analgesia for pain while at rest (odds ratio [OR], $1.81,95 \% \mathrm{Cl}: 1.14-2.87, P=0.011$, and $\mathrm{OR}$, $1.01,95 \% \mathrm{Cl}: 1.00-1.01, P=0.020$, respectively).Tramadol combined with flurbiprofen axetil was identified as a protective factor for inadequate analgesia for pain while at rest (OR, $0.29,95 \% \mathrm{Cl}: 0.21-0.39, P<0.001)$.

As shown in Table 2, placenta disease and intraoperative blood loss were identified as significant factors for inadequate analgesia for moving pain (OR, 1.65, 95\% Cl: 1.20-2.26, $P=0.002$ and $\mathrm{OR}, 1.00,95 \% \mathrm{Cl}: 1.00-1.00, P=0.005$, respectively). Tramadol combined with flurbiprofen axetil was a protective factor of inadequate analgesia for moving pain (OR, $0.38,95 \% \mathrm{Cl}$ : $0.33-0.44, P<0.001)$, while tramadol in combination with butorphanol was a risk factor of inadequate analgesia for moving pain $(\mathrm{OR}, 1.73,95 \% \mathrm{Cl}: 1.48-2.01, P<0.001)$.

\section{Group F Versus Group B}

The demographic and preoperative baseline data of group $\mathrm{F}$ and group $\mathrm{B}$ are shown in Table 3 . There were significant differences between the-groups regarding the duration of operation and blood loss during the operation (both, $P<0.05)$. No significant difference was found in other preoperative parameters ( $P>0.05)$. After PSM, no significant difference in the demographic and preoperative baseline data was observed between the two groups $(P>0.05)$.

As shown in Table 4, compared to group B, the incidence of inadequate analgesia at rest and while moving was lower in group $F$, and the RRs for women with puerperas suffering from inadequate analgesia at rest and while moving in group $F$ were 0.34 ( $95 \%$ Cl: $0.21-0.54 ; P<0.001)$ and 0.24 (95\% Cl: $0.19-0.31, P<0.001)$, respectively. The incidences of off-bed activity and intestinal function recovery at 2 days after caesarean delivery were higher in group $B$ than in group $\mathrm{F}(79.4 \%$ versus [vs.] $66.4 \%, P<0.001$ and 74.1 vs. $66.4, P=0.006$, respectively). The length of hospitalisation was also shorter in group $F$ than in the group $B$ $(3.33 \pm 1.43$ vs. $3.77 \pm 1.54, P<0.001)$ (Table 4$)$.

\section{Group F Versus Group T}

As shown in Table 5, there were significant between-group differences in the length of operative time and incidence of primiparas or multiparas (both, $P<0.05$ ). No significant between-group difference was found in the demographic and preoperative baseline parameters ( $P$ 0.05). After PSM, no significant differences in any of the demographic and preoperative baseline date was observed between the two groups ( $P>0.05)$.

As shown in Table 6, group $\mathrm{F}$ was associated with a lower incidence of inadequate control of pain at rest and while moving than group T (RR, 0.37 [0.23-0.60], $P<0.001$ and RR, 0.43 [0.33-0.55], $P<0.001$, respectively). The length of hospitalisation stay and hospitalisation cost were lower in group $\mathrm{F}$ than in group $\mathrm{T}(P<0.05)$. No significant differences were found in the incidences of off-bed activity and intestinal function recovery at 2 days after caesarean delivery between the two groups (P>0.05).

\section{Group B Versus Group T}

The demographic and preoperative baseline data of group B and group T are shown in Table 7. Before PSM, the incidence of placenta disease was significantly different between the two groups $(P<0.05)$. After PSM, no significant between-group difference was found in demographic and other baseline data between the groups $(P>0.05)$.

Group B was associated with a higher incidence of inadequate control of moving pain than group T (RR, 1.78 [1.40-2.26], $P<0.001)$. Compared to group $T$, the hospitalisation cost was lower in group B $(13225.40 \pm 3455.06$ vs.14767.75 \pm 3574.63 , $P<0.001)$, and the percentage of off-bed activity at 2 days postoperative was higher in group B $(79.4 \%$ vs.64.4\%) (Table 8).

\section{Discussion}


To the best of our knowledge, this is the first study to explore the potential differences in postoperative analgesia among tramadol alone and tramadol combined with butorphanol or flurbiprofen axetil after caesarean section through retrospective analysis. Our results were confirmed in the propensity score-matched cohort after using PSM analysis. This finding shows that the incidence of inadequate analgesia was highest with tramadol combined with butorphanol, and tramadol combined with flurbiprofen axil had an optimal analgesic effect. However, in group B, off-bed activity and intestinal function recovery after caesarean delivery occurred the earliest.

Multimodal analgesia is currently advocated because of its superior analgesic effect and reduction of adverse reactions, but there are many options for multimodal analgesia strategies. The United States Food and Drug Administration recommends avoiding the co-administration of mixed agonist-antagonists and full opioid agonist use because of the diminishing analgesic effect. One study also reported that butorphanol has a partial reverse antagonistic effect for intravenously administered hydromorphone.[17] The side effects of hydromorphone can be reduced and the degree of reduction is dose-dependent.[17] However, some anaesthesiologists still prefer to co-administer agonist-antagonist and agonists for postoperative analgesia or to administer agonist-antagonist for supplementation of pain relief after agonist use.[18] They believe that this method can enhance the analgesic effect while reducing the adverse reactions of opioids for postoperative analgesia.

Tramadol is a weak mu receptor agonist, and butorphanol is an agonist-antagonist analgesic drug. Some anaesthesiologists use tramadol combined with butorphanol for postoperative analgesia,[19]and a study reported that tramadol combined with butorphanol has a stronger analgesic effect than sufentanil for caesarean section analgesia;[20] however, the comparison between tramadol combined with butorphanol and these two drugs alone was not performed in this study. Our study found that the incidence of inadequate analgesia was higher in group B (800 mg of tramadol combined with $2 \mathrm{mg}$ of butorphanol for PCIA in 2 days) than in groups $F$ and $T$, but off-bed activity and intestinal function recovery occurred earliest in group B. We hypothesised that butorphanol produced an antagonistic effect on tramadol, which attenuated the analgesic effect and reduced the adverse effects of inhibiting gastrointestinal function. Therefore, whether the analgesic method of butorphanol combined with tramadol is reasonable and whether we should change the analgesic strategy is worth further consideration.

Flurbiprofen axetil plays analgesic and anti-inflammatory effects by reducing the release of prostaglandin through inhibiting cyclooxygenase activity. Studies have verified that UCP is associated with an increased release of prostaglandin[21, 22].Coadministration of tramadol and flurbiprofen axetil has a definite analgesic effect. [23,24] Our study found that tramadol combined with flurbiprofen axetil has the optimal analgesic effect for caesarean sections. Therefore, the analgesia strategy of tramadol combined with flurbiprofen axetil is a good choice for obstetric analgesia.

Several limitations should be considered when evaluating the results of the present study. First, some limitations in data collection were unavoidable because this was a retrospective study. Second, since it is difficult to distinguish between visceral pain and incision pain, visceral pain was not recorded separately, so this should be further studied in the future. Third, a mechanical pump was used for PCIA in our hospital. Because the pump could not record the analgesic consumption, we did not report the analgesic use between the groups in this study; we only recorded the extra analgesia requirement, so this should be further studied in the future.

\section{Conclusion}

In conclusion, a combination of tramadol and flurbiprofen axetil enhanced the analgesic effect and was safely used for analgesia after caesarean section, but the combination of tramadol and butorphanol may produce an antagonistic effect.

\section{Abbreviations}

OR: Odds ratio; RRs: relative risks; $\mathrm{Cl}$ : Confidence interval; BMI: body mass index; PCIA: patient-controlled intravenous analgesia; PCEA: patient-controlled epidural analgesia; OT: oxytocin; CP: uterine cramping pain

\section{Declarations}




\section{Ethics approval and informed consent}

The study protocol was approved by the Institutional Ethics Committee of Second Affiliated Hospital of Army Medical University, Chongqing, China (approved ID: 2019-040-1). Informed consent was avoided by the Ethics Committee of Second Affiliated Hospital of Army Medical University. All the methods were performed in common with the Declaration of GCP, Helsinki, ICH-GCP and relevant rule in China.

\section{Consent for publication}

Not applicable.

\section{Availability of data and materials}

All data can be acquired from the corresponding author $(\mathrm{HL})$ by request.

\section{Competing interests}

The authors declare no competing interests.

\section{Funding}

The study was supported by Natural Science Foundation in Chongqing (No. CSTC2020JCYJ-MSXMX0453), and National Key Research and Development Project (2018YFC0117200)

\section{Authors' contributions}

Xiaohang Bao: Research Design, Data Collection; Guiying Yang: Funding acquisition, Writing-original draft; Jing Peng: Data Collection $₫$ Wenjun Liu: Data Collection;Yan Liang: Data Collection; Mingming Wang: Data Collection; Guangming Yan: Data Collection; Dan Tan: Data Collection; Zhuoxi Wu: Data Analysis, Qiangting Deng: Data Analysis; Hong Li: Funding acquisition, Writing - review \& editing. The final manuscript was read and approved by all authors.

\section{Acknowledgments}

Not applicable

\section{Author details}

${ }^{1}$ Department of Anesthesiology, Second Affiliated Hospital of Army Medical University, Chongqing, 400037, China. ${ }^{2}$ Editorial Office of Journal of Third Military Medical University, Army Medical University, Chongqing 400038, China. ${ }^{3}$ Department of Emergency, Second Affiliated Hospital of Army Medical University, Chongqing, 400037, China.

\section{References}

1. C. M. Ortner MGPR: Preoperative scar hyperalgesia is associated with post-operative pain in women undergoing a repeat Caesarean delivery. EUR J PAIN2013(No.1):111-123.doi: 10.1002/j.1532-2149.2012.00171.x.

2. Patel R, Carvalho JCA, Downey K, Kanczuk M, Bernstein P, Siddiqui N: Intraperitoneal Instillation of Lidocaine Improves Postoperative Analgesia at Cesarean Delivery: A Randomized, Double-Blind, Placebo-Controlled Trial. ANESTH ANALG 
2017(No.2):554-559.doi: 10.1213/ANE.0000000000001799.

3. van Wijck AJM, Aduckathil S, Kalkman CJ, Gerbershagen HJ, Peelen LM: Pain Intensity on the First Day after Surgery A Prospective Cohort Study Comparing 179 Surgical Procedures. ANESTHESIOLOGY 2013(No.4):934-944.DOI: 10.1097/ALN.0b013e31828866b3

4. Jeanette R Bauchat CFWP: Society for Obstetric Anesthesia and Perinatology Consensus Statement: Monitoring Recommendations for Prevention and Detection of Respiratory Depression Associated With Administration of Neuraxial Morphine for Cesarean Delivery Analgesia. ANESTH ANALG 2019(No.2):458-474.doi: 10.1213/ANE.0000000000004195.

5. T U, S H, H I, K K, J T, A M, M M, T N: Use of imaging agent to determine postoperative indwelling epidural catheter position. Korean J Pain 2010(No.4):247-253.doi: 10.3344/kjp.2010.23.4.247. Epub 2010 Dec 1.

6. Odonkor PN, Deshpande SP, Malinow AM: An Impacted Epidural Catheter. ANESTHESIOLOGY2019(No.3):664.doi: 10.1097/ALN.0000000000002738.

7. Bomberg HBH, Bayer IBI, Wagenpfeil SWS, Kessler PKP, Wulf HWH, Standl TST, Gottschalk AGA, Doffert JDJ, Hering WHW, Birnbaum JBJ et al: Prolonged Catheter Use and Infection in Regional Anesthesia: A Retrospective Registry Analysis. ANESTHESIOLOGY 2018(No.4):764-773.doi: 10.1097/ALN.0000000000002105.

8. Obstetrics ACOO: ACOG Practice Bulletin No. 209: Obstetric Analgesia and Anesthesia(Article). OBSTET GYNECOL 2019(No.3):e208-e225. DOI: 10.1097/AOG.0000000000003132

9. Vazzana M, Andreani T, Fangueiro J, Faggio C, Silva C, Santini A, Garcia ML, Silva AM, Souto EB: Tramadol hydrochloride: Pharmacokinetics, pharmacodynamics, adverse side effects, co-administration of drugs and new drug delivery systems. BIOMED PHARMACOTHER 2015:234-238. doi: 10.1016/j.biopha.2015.01.022. Epub 2015 Feb 7.

10. Zhuoxi Wu PZJP: A Patient-Controlled Intravenous Analgesia With Tramadol Ameliorates Postpartum Depression in HighRisk Woman After Cesarean Section: A Randomized Controlled Trial. Frontiers in medicine 2021:679159.doi: 10.3389/fmed.2021.679159. eCollection 2021.

11. Duan GDG, Bao XBX, Yang GYG, Peng JPJ, Wu ZWZ, Zhao PZP, Zuo ZZZ, Li HLH: Patient-controlled intravenous tramadol versus patient-controlled intravenous hydromorphone for analgesia after secondary cesarean delivery: a randomized controlled trial to compare analgesic, anti-anxiety and anti-depression effects. J PAIN RES 2019:49-59. doi: 10.2147/JPR.S184782.

12. Yadav J, Regmi MC, Basnet P, Guddy KM, Bhattarai B, Poudel P: Butorphanol in Labour Analgesia. JNMA; journal of the Nepal Medical Association 2018(No.214):940-944.

13. Pokharel KA, Rahman TRA, Singh SNA, Bhattarai BA, Basnet NB, Khaniya SC: The efficacy and safety of low dose-epidural buforphanol on postoperative analgesia following cesarean delivery(Article). Journal of the Nepal Medical Association 2008(No.170):57-61.

14. Hsu HHH, Cheng YCY, Chen LCL, Wang YWY, Lin CLC, Lee CLC, Sun WSW: Differential analgesic effect of tenoxicam on the wound pain and uterine cramping pain after cesarean section. CLIN J PAIN2003(No.1):55-58.doi: 10.1097/00002508200301000-00007

15. Kimura M, Okamoto T, Tsukagoshi H, Sato J, Saito S: Effect of flurbiprofen, metoclopramide and droperidol for nausea and emesis during cesarean section under spinal anesthesia. J ANESTH2011(No.5):692-697.doi: 10.1007/s00540-011-1203-7.

16. Ishiyama T, Yamaguchi T, Kashimoto S, Kumazawa T: Effects of epidural fentanyl and intravenous flurbiprofen for visceral pain during cesarean section under spinal anesthesia. J ANESTH 2001(No.2):69-73.doi: 10.1007/s005400170029.

17. BT S, EM S, CL B, CD C, I L: The antinociceptive effects of intravenous administration of three doses of butorphanol tartrate or naloxone hydrochloride following hydromorphone hydrochloride to healthy conscious cats. VET ANAESTH ANALG 2019(No.4):538-547.doi: 10.1016/j.vaa.2019.04.006.

18. Groppetti D, Pecile AM, Sacerdote P: Effectiveness of electroacupuncture analgesia compared with opioid administration in a dog model: a pilot study. BRIT J ANAESTH2011(No.4):612-618.doi: 10.1093/bja/aer199.

19. Zhu J, Xu C, Wang X, Shi W: Comparison of the analgesic effects of dezocine, tramadol and butorphanol after cesarean section. PAK J PHARM SCI 2018(Suppl Special):2191-2195. 
20. Cai Q, Gong H, Fan M, Chen W, Cai L: The analgesic effect of tramadol combined with butorphanol on uterine cramping pain after repeat caesarean section: a randomized, controlled, double-blind study. J ANESTH2020(No.6):825-833.doi:

10.1007/s00540-020-02820-9.

21. Hellman KHK, Yu PYP, Oladosu FOF, Segel CSC, Han AHA, Prasad PPP, Jilling TJT, Tu FTF: The Effects of Platelet-Activating Factor on Uterine Contractility, Perfusion, Hypoxia, and Pain in Mice. REPROD SCI 2018(No.3):384-394. doi: $10.1177 / 1933719117715122$.

22. Chiang $\mathrm{Y}$, Hung H, Chen H, Huang K, Lin P, Chang J, Huang T, Hsia S: The Inhibitory Effect of Extra Virgin Olive Oil and Its Active Compound Oleocanthal on Prostaglandin-Induced Uterine Hypercontraction and Pain-Ex Vivo and In Vivo Study. NUTRIENTS 2020(No.3012):3012. doi: 10.3390/nu12103012.

23. Wang JWJ, Li HLH, Ma HMH, Wang NWN: Effect of Preemptive Flurbiprofen Axetil and Tramadol on Transurethral Resection of the Prostate under Spinal Anesthesia. Pain Research and Treatment 2016:3942040.doi: 10.1155/2016/3942040.

24. R M, M S, H K, T O, M S, M T, T M: Effect of continuous intravenous infusion of flurbiprofen axetil and tramadol hydrochloride for postoperative pain management after laparoscopic colectomy. Masui. The Japanese Journal Of Anesthesiology 2011(No.12):1364-1369.

\section{Tables}

\section{Table 1}

Factors with on inadequate analgesia(rest pain) in stepwise logistic regression analysis for all groups.

\begin{tabular}{llllll} 
Subjects & Factors with & Wald & P value & OR & $95 \% \mathrm{Cl}$ \\
\hline All maternal women $(\mathrm{n}=2323)$ & Placenta disease & 6.40 & 0.011 & 1.81 & 1.14 to 2.87 \\
\hline & Duration of operation & 5.42 & 0.020 & 1.01 & 1.00 to 1.01 \\
\hline & Combined with & 68.83 & $<0.001$ & 0.29 & 0.21 to 0.39
\end{tabular}

$\mathrm{Cl}=$ Confidence interval; $\mathrm{OR}=$ Odds rate

Table 2

Factors with on inadequate analgesia(moving pain) in stepwise logistic regression analysis for all groups.

\begin{tabular}{llllll} 
Subjects & Factors with & Wald & $P$ value & OR & $95 \% \mathrm{Cl}$ \\
\hline \multirow{2}{*}{ All maternal women $(\mathrm{n}=2323)$} & Placenta disease & 9.60 & 0.002 & 1.65 & 1.20 to 2.26 \\
\cline { 2 - 6 } & Intraoperative blood loss & 8.03 & 0.005 & 1.00 & 1.00 to 1.00 \\
\hline & Combined with & 154.69 & $<0.001$ & 0.38 & 0.33 to 0.44 \\
\hline & Combined with butorphanol & 49.35 & $<0.001$ & 1.73 & 1.48 to 2.01 \\
\hline
\end{tabular}

$\mathrm{Cl}=$ Confidence interval; OR = Odds rate

\section{Table 3}

Demographic and preoperative baseline data for patients in group F and group B. 


\begin{tabular}{|c|c|c|c|c|c|c|c|c|}
\hline & \multicolumn{3}{|c|}{ non-matched patients } & \multicolumn{5}{|c|}{ matched patients } \\
\hline & $\begin{array}{l}\text { Group } \\
F(n=1058)\end{array}$ & Group B(n=601) & $\begin{array}{l}P \\
\text { values }\end{array}$ & $\begin{array}{l}\text { Bonferroni } \\
\text { correction }\end{array}$ & $\begin{array}{l}\text { Group } \\
F(n=553)\end{array}$ & $\underset{(n=553)}{\operatorname{group}}$ & $\begin{array}{l}P \\
\text { values }\end{array}$ & $\begin{array}{l}\text { Bonferroni } \\
\text { correction }\end{array}$ \\
\hline Age (year) & $30.4 \pm 4.4$ & $30.4 \pm 6.2$ & 0.871 & $>0.99$ & $30.4 \pm 4.6$ & $30.4 \pm 4.3$ & 0.968 & $>0.99$ \\
\hline $\operatorname{BMI}\left(\mathrm{kg} / \mathrm{m}^{2}\right)$ & $27.7 \pm 3.9$ & $27.6 \pm 3.4$ & 0.639 & $>0.99$ & $27.5 \pm 3.4$ & $27.6 \pm 3.3$ & 0.654 & $>0.99$ \\
\hline $\begin{array}{l}\text { Duration of } \\
\text { operation(min) }\end{array}$ & $84 \pm 34$ & $80 \pm 25$ & 0.001 & 0.002 & $80 \pm 22$ & $80 \pm 24$ & 0.670 & $>0.99$ \\
\hline $\begin{array}{l}\text { Intraoperative } \\
\text { blood loss (mL) }\end{array}$ & $341 \pm 268$ & $308 \pm 188$ & 0.008 & 0.016 & $314 \pm 172$ & $313 . \pm 184$ & 0.906 & $>0.99$ \\
\hline Placenta disease & $89(8.4 \%)$ & $34(5.7 \%)$ & 0.040 & 0.080 & 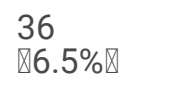 & $33 \llbracket 6.0 \% \rrbracket$ & 0.709 & $>0.99$ \\
\hline $\begin{array}{l}\text { or } \\
\text { polyhydramnios }\end{array}$ & $72(6.8 \%)$ & $34(5.7 \%)$ & 0.358 & 0.616 & $\begin{array}{l}42 \\
\square 7.6 \% \bigotimes\end{array}$ & $31 \rrbracket 5.7 \% \rrbracket$ & 0.165 & 0.330 \\
\hline $\begin{array}{l}\text { Prediagnosed } \\
\text { fetal disease }\end{array}$ & $17(1.6 \%)$ & $14(2.3 \%)$ & 0.290 & 0.580 & 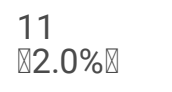 & $14 \llbracket 2.5 \% \rrbracket$ & 0.544 & $>0.99$ \\
\hline $\begin{array}{l}\text { Premature } \\
\text { rupture of } \\
\text { membrane }\end{array}$ & $101(9.6 \%)$ & $76(12.7 \%)$ & 0.049 & 0.098 & $\begin{array}{l}52 \\
\square 9.4 \% \bigotimes\end{array}$ & $\begin{array}{l}73 \\
\square 13.2 \% \bigotimes\end{array}$ & 0.046 & 0.092 \\
\hline Hypertension & $80(7.6 \%)$ & $39(7.0 \%)$ & 0.416 & 0.832 & $\begin{array}{l}55 \\
\square 9.9 \% \square\end{array}$ & $35 \rrbracket 6.9 \% \rrbracket$ & 0.065 & 0.130 \\
\hline $\begin{array}{l}\text { Gestational } \\
\text { diabetes }\end{array}$ & $108(10.2 \%)$ & $71(11.8 \%)$ & 0.311 & 0.622 & $\begin{array}{l}56 \\
\otimes 10.1 \% \square\end{array}$ & $\begin{array}{l}58 \\
\square 10.5 \% \square\end{array}$ & 0.843 & $>0.99$ \\
\hline $\begin{array}{l}\text { Hyperthyroidism } \\
\text { or } \\
\text { hypothyroidism }\end{array}$ & $62(5.9 \%)$ & $39(6.5 \%)$ & 0.607 & $>0.99$ & $\begin{array}{l}32 \\
\otimes 5.8 \% \bigotimes\end{array}$ & $38 \bowtie 6.9 \% \rrbracket$ & 0.459 & 0.918 \\
\hline \multirow{2}{*}{$\begin{array}{l}\text { History of } \\
\text { surgery }\end{array}$} & $19(1.8 \%)$ & $9(1.5 \%)$ & 0.650 & $>0.99$ & $8 \bigotimes 1.4 \% \bigotimes$ & $9 \rrbracket 1.6 \% \rrbracket$ & 0.807 & $>0.99$ \\
\hline & $\begin{array}{l}120 \\
(11.3 \%)\end{array}$ & $57(9.5 \%)$ & 0.239 & 0.478 & $\begin{array}{l}60 \\
\square 10.8 \% \square\end{array}$ & $53 \llbracket 9.6 \% \rrbracket$ & 0.487 & 0.894 \\
\hline $\begin{array}{l}\text { Synchronized } \\
\text { other surgery }\end{array}$ & $\begin{array}{l}115 \\
(10.9 \%)\end{array}$ & 61 (10.5\%) & 0.642 & $>0.99$ & $\begin{array}{l}59 \\
\square 10.7 \% \square\end{array}$ & $56 \varangle 9.8 \% \rrbracket$ & 0.641 & $>0.99$ \\
\hline $\begin{array}{l}\text { Primiparas or } \\
\text { multiparas }\end{array}$ & 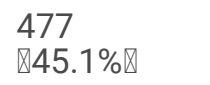 & $247 \rrbracket 41.1 \% \rrbracket$ & 0.116 & 0.232 & $\begin{array}{l}221 \\
\square 40.0 \% \rrbracket\end{array}$ & $\begin{array}{l}218 \\
\bigotimes 39.4 \% \square\end{array}$ & 0.854 & $>0.99$ \\
\hline
\end{tabular}

Table 4

Intraoperative and postoperative outcomes for matched patients group F and group B. 


\begin{tabular}{|c|c|c|c|c|}
\hline & Group F $(n=553)$ & $\begin{array}{l}\text { Group } \\
B(n=553)\end{array}$ & $\begin{array}{l}P \\
\text { values }\end{array}$ & $\begin{array}{l}\text { Bonferroni } \\
\text { correction }\end{array}$ \\
\hline Inadequate analgesia(rest pain ) & $24 \llbracket 4.5 \% \rrbracket$ & $68 \bigotimes 12.3 \% \bigotimes$ & $<0.001$ & $<0.001$ \\
\hline Inadequate analgesia(moving pain) & $137 \rrbracket 24.8 \% \rrbracket$ & $326 \otimes 59.1 \% \bigotimes$ & $<0.001$ & $<0.001$ \\
\hline Extra analgesia requirement & $6(1.1 \%)$ & $14(2.5 \%)$ & 0.078 & $>0.99$ \\
\hline Dizziness & $5 \rrbracket 0.9 \rrbracket$ & $9 \rrbracket 1.6 \rrbracket$ & 0.564 & $>0.99$ \\
\hline Nausea and vomiting & $9(1.6 \%)$ & $11(2.0 \%)$ & 0.652 & $>0.99$ \\
\hline Off-bed activity at 2 day after cesarean delivery & $376(66.4 \%)$ & $439(79.4 \%)$ & $<0.001$ & $<0.001$ \\
\hline $\begin{array}{l}\text { Intestinal function recovery at } 2 \text { day after cesarean } \\
\text { delivery }\end{array}$ & $367(66.4 \%)$ & $410(74.1 \%)$ & 0.003 & 0.006 \\
\hline Hospitalisation stay(day) & $3.3 \pm 1.4$ & $3.8 \pm 1.5$ & $<0.001$ & $<0.001$ \\
\hline Hospitalisation cost(yuan) & $13288 \pm 3403$ & $13235 \pm 3455$ & 0.785 & $>0.99$ \\
\hline
\end{tabular}

Table 5

Demographic and preoperative baseline data for patients in group $\mathrm{F}$ and group $\mathrm{T}$. 
non-matched patients

matched patients

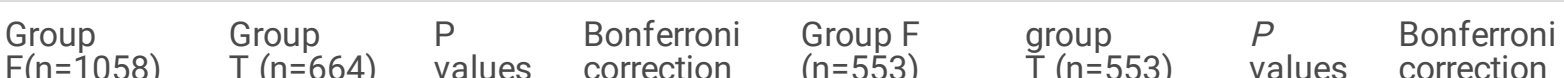

\begin{tabular}{|c|c|c|c|c|c|c|c|c|}
\hline Age (year) & $30.4 \pm 4.4$ & $30.6 \pm 4.6$ & 0.480 & $>0.99$ & $30.4 \pm 4.6$ & $30.4 \pm 4.4$ & 0.915 & $>0.99$ \\
\hline BMI (kg/m2) & $27.6 \pm 3.6$ & $27.7 \pm 3.4$ & 0.791 & $>0.99$ & $27.5 \pm 3.4$ & $27.6 \pm 3.4$ & 0.549 & $>0.99$ \\
\hline $\begin{array}{l}\text { Duration of } \\
\text { operation } \rrbracket \min \rrbracket\end{array}$ & $84 \pm 34$ & $80 \pm 23$ & 0.001 & 0.002 & $80 \pm 22$ & $80 \pm 23$ & 0.566 & $>0.99$ \\
\hline $\begin{array}{l}\text { Intraoperative } \\
\text { blood loss }(\mathrm{mL})\end{array}$ & $341 \pm 268$ & $325 \pm 207$ & 0.214 & 0.428 & $314 \pm 172$ & $317 \pm 189$ & 0.816 & $>0.99$ \\
\hline Placenta disease & $89(8.4 \%)$ & $66(9.9 \%)$ & 0.281 & 0.562 & $36 \rrbracket 6.5 \% \rrbracket$ & $32 \rrbracket 5.8 \% \rrbracket$ & 0.617 & $>0.99$ \\
\hline $\begin{array}{l}\text { or } \\
\text { polyhydramnios }\end{array}$ & $72(6.8 \%)$ & $31(4.7 \%)$ & 0.069 & 0.138 & $42 \bigotimes 7.6 \% \rrbracket$ & $27 ه 4.9 \% \rrbracket$ & 0.071 & 0.142 \\
\hline $\begin{array}{l}\text { Prediagnosed } \\
\text { fetal disease }\end{array}$ & $17(1.6 \%)$ & $11(1.7 \%)$ & 0.937 & $>0.99$ & $11 \rrbracket 2.0 \% \rrbracket$ & $9 \otimes 1.6 \% \rrbracket$ & 0.652 & $>0.99$ \\
\hline $\begin{array}{l}\text { Premature rupture } \\
\text { of membrane }\end{array}$ & $101(9.6 \%)$ & $69(10.4 \%)$ & 0.567 & $>0.99$ & $52(9.4 \%)$ & $62(11.2 \%)$ & 0.270 & 0.540 \\
\hline Hypertension & $80(7.6 \%)$ & $40(6.0 \%)$ & 0.223 & 0.446 & $55 \otimes 9.9 \% \bigotimes$ & $38 \bowtie 6.8 \% \rrbracket$ & 0.055 & 0.110 \\
\hline $\begin{array}{l}\text { Gestational } \\
\text { diabetes }\end{array}$ & $108(10.2 \%)$ & $70(10.5 \%)$ & 0.825 & $>0.99$ & $5 \otimes 10.1 \% \bigotimes$ & $60(10.8 \% \rrbracket$ & 0.695 & $>0.99$ \\
\hline $\begin{array}{l}\text { Hyperthyroidism } \\
\text { or } \\
\text { hypothyroidism }\end{array}$ & $62(5.9 \%)$ & $39(5.9 \%)$ & 0.991 & $>0.99$ & $32 \bowtie 5.8 \% \rrbracket$ & $35 \rrbracket 6.3 \% \rrbracket$ & 0.075 & 0.150 \\
\hline \multirow[t]{2}{*}{ History of surgery } & $19(1.8 \%)$ & $12(1.8 \%)$ & 0.986 & $>0.99$ & $8(1.4 \%)$ & $12(2.2 \%)$ & 0.373 & $>0.99$ \\
\hline & $\begin{array}{l}120 \\
(11.3 \%)\end{array}$ & $54(8.1 \%)$ & 0.031 & 0.062 & $60(10.8 \%)$ & $39(7.1 \%)$ & 0.027 & 0.054 \\
\hline $\begin{array}{l}\text { Synchronized } \\
\text { other surgery }\end{array}$ & $\begin{array}{l}115 \\
(10.9 \%)\end{array}$ & $69(10.4 \%)$ & 0.755 & $>0.99$ & $59(10.7 \%)$ & $53(9.6 \%)$ & 0.570 & $>0.99$ \\
\hline $\begin{array}{l}\text { Primiparas or } \\
\text { multiparas }\end{array}$ & $47 \rrbracket 45.1 \% \bigotimes$ & $\begin{array}{l}25 \\
\rrbracket 37.8 \% \rrbracket\end{array}$ & 0.003 & 0.006 & $221(40.0 \%)$ & $220(39.8 \%)$ & 0.921 & $>0.99$ \\
\hline
\end{tabular}

Data were presented as Means \pm SD, or as numbers (frequency); BMI=body mass index.

Table 6

Intraoperative and postoperative outcomes for matched patients in group $\mathrm{F}$ and group $\mathrm{T}$. 


\begin{tabular}{|c|c|c|c|c|}
\hline & $\begin{array}{l}\text { Group } \\
F(n=553)\end{array}$ & $\begin{array}{l}\text { Group T } \\
(n=553)\end{array}$ & $\begin{array}{l}P \\
\text { values }\end{array}$ & $\begin{array}{l}\text { Bonferroni } \\
\text { correction }\end{array}$ \\
\hline Inadequate analgesia(rest pain ) & $25 \llbracket 4.5 \% \rrbracket$ & $63 \rrbracket 11.6 \% \bigotimes$ & $<0.001$ & $<0.001$ \\
\hline Inadequate analgesia(moving pain) & $137 \rrbracket 24.8 \% \rrbracket$ & $241 \rrbracket 43.6 \% \rrbracket$ & $<0.001$ & $<0.001$ \\
\hline Extra analgesia requirement & $6(1.1 \%)$ & $4(0.7 \%)$ & 0.525 & $>0.99$ \\
\hline Dizziness & $5 \rrbracket 0.9 \% \rrbracket$ & $4 \llbracket 0.7 \% \rrbracket$ & 0.738 & $>0.99$ \\
\hline Nausea and vomiting & $9 \rrbracket 1.6 \% \rrbracket$ & $11(2.0 \% \square$ & 0.652 & $>0.99$ \\
\hline Off-bed activity at 2 day after cesarean delivery & $376 \llbracket 68.0 \% \rrbracket$ & $356 \otimes 64.4 \% \bigotimes$ & 0.204 & 0.408 \\
\hline $\begin{array}{l}\text { Intestinal function recovery at } 2 \text { day after cesarean } \\
\text { delivery }\end{array}$ & $367 \rrbracket 66.4 \% \rrbracket$ & $371 \otimes 67.2 \% \rrbracket$ & 0.779 & $>0.99$ \\
\hline Hospitalisation stay(day) & $3.3 \pm 1.4$ & $3.7 \pm 1.6$ & 0.001 & 0.002 \\
\hline Hospitalisation cost(yuan) & $13287 \pm 3403$ & $14768 \pm 3575$ & $<0.001$ & $<0.001$ \\
\hline
\end{tabular}

Table 7

Demographic and preoperative baseline data for matched patients in group B and group T. 
non-matched patients

matched patients

\begin{tabular}{|c|c|c|c|c|c|c|}
\hline $\begin{array}{l}\text { Group B } \\
(n=601)\end{array}$ & $\begin{array}{l}\text { Group } \\
T(n=664)\end{array}$ & $\begin{array}{l}P \\
\text { values }\end{array}$ & $\begin{array}{l}\text { Bonferroni } \\
\text { correction }\end{array}$ & $\begin{array}{l}\text { Group } \\
B(n=553)\end{array}$ & $\begin{array}{l}\text { Group } \\
T(n=553)\end{array}$ & $P$ values \\
\hline
\end{tabular}

\begin{tabular}{|c|c|c|c|c|c|c|c|c|}
\hline Age (year) & $30.3 \pm 6.2$ & $30.6 \pm 4.6$ & 0.529 & $>0.99$ & $30.4 \pm 4.3$ & $30.4 \pm 4.4$ & 0.152 & 0.304 \\
\hline $\mathrm{BMI}\left(\mathrm{kg} / \mathrm{m}^{2}\right)$ & $27.6 \pm 3.4$ & $27.7 \pm 3.4$ & 0.676 & $>0.99$ & $27.6 \pm 3.3$ & $27.6 \pm 3.4$ & 0.549 & $>0.99$ \\
\hline $\begin{array}{l}\text { Duration of } \\
\text { operation(min) }\end{array}$ & $80 \pm 25$ & $79 \pm 23$ & 0.509 & $>0.99$ & $80 \pm 24$ & $80 \pm 23$ & 0.890 & $>0.99$ \\
\hline $\begin{array}{l}\text { Intraoperative } \\
\text { blood loss (mL) }\end{array}$ & $308 \pm 188$ & $325 \pm 207$ & 0.509 & $>0.99$ & $313 \pm 184$ & $317 \pm 189$ & 0.735 & $>0.99$ \\
\hline $\begin{array}{l}\text { Placenta } \\
\text { disease }\end{array}$ & $34(5.7 \%)$ & $66(9.9 \%)$ & 0.005 & 0.010 & $33 \rrbracket 6.0 \% \rrbracket$ & $32 \rrbracket 5.8 \% \bigotimes$ & 0.898 & $>0.99$ \\
\hline $\begin{array}{l}\text { or } \\
\text { polyhydramnios }\end{array}$ & $34(5.7 \%)$ & $31(4.7 \%)$ & 0.426 & $>0.852$ & $31 \rrbracket 5.7 \% \rrbracket$ & $27 ه 4.9 \% \bigotimes$ & 0.541 & $>0.99$ \\
\hline $\begin{array}{l}\text { Prediagnosed } \\
\text { fetal disease }\end{array}$ & $14(2.3 \%)$ & $11(1.7 \%)$ & 0.391 & $>0.782$ & $14 \rrbracket 2.5 \% \bigotimes$ & $9 \rrbracket 1.6 \% \rrbracket$ & 0.292 & 0.584 \\
\hline $\begin{array}{l}\text { Premature } \\
\text { rupture of } \\
\text { membrane }\end{array}$ & $76(12.6 \%)$ & $69(10.4 \%)$ & 0.209 & 0.418 & $73 \rrbracket \% \bigotimes$ & $62 \rrbracket \% \square$ & 0.312 & 0.624 \\
\hline Hypertension & $39(6.5 \%)$ & $40(6.0 \%)$ & 0.733 & $>0.99$ & $35 \rrbracket 6.9 \% \rrbracket$ & $38 \rrbracket 6.8 \% \rrbracket$ & 0.063 & 0.126 \\
\hline $\begin{array}{l}\text { Gestational } \\
\text { diabetes }\end{array}$ & 71 (11.8\%) & $70(10.6 \%)$ & 0.473 & $>0.946$ & $58(10.5 \%)$ & $60(10.8 \%)$ & 0.846 & $>0.99$ \\
\hline $\begin{array}{l}\text { Hyperthyroidism } \\
\text { or } \\
\text { hypothyroidism }\end{array}$ & $39(6.2 \%)$ & $39(5.9 \%)$ & 0.816 & $>0.99$ & $38 \rrbracket 6.8 \% \rrbracket$ & $35 \rrbracket 6.3 \% \rrbracket$ & 0.716 & $>0.99$ \\
\hline \multirow{2}{*}{$\begin{array}{l}\text { History of } \\
\text { surgery }\end{array}$} & $9(1.5 \%)$ & $12(1.8 \%)$ & 0.667 & $>0.99$ & $9 \otimes 1.6 \% \bigotimes$ & $12 \bigotimes 2.2 \% \bigotimes$ & 0.514 & $>0.99$ \\
\hline & $57(9.5 \%)$ & $54(8.1 \%)$ & 0.396 & $>0.792$ & $53 \rrbracket 9.6 \% \rrbracket$ & 39ه7.1\%》 & 0.127 & 0.254 \\
\hline $\begin{array}{l}\text { Synchronized } \\
\text { other surgery }\end{array}$ & $61(10.1 \%)$ & $69(10.4 \%)$ & 0.856 & $>0.99$ & $56 \rrbracket 9.8 \% \rrbracket$ & $53 \rrbracket 9.6 \% \rrbracket$ & 0.739 & $>0.99$ \\
\hline $\begin{array}{l}\text { Primiparas or } \\
\text { multiparas }\end{array}$ & $247(41.1 \%)$ & $251(37.8 \%)$ & 0.231 & 0.462 & $218 \rrbracket 39.4 \% \rrbracket$ & $\begin{array}{l}220 \\
\square 39.8 \% \rrbracket\end{array}$ & 0.902 & $>0.99$ \\
\hline
\end{tabular}

Data were presented as Means $\pm \mathrm{SD}$, or as numbers (frequency); BMl=body mass index.

Table 8

Intraoperative and postoperative outcomes for matched patients in group B and group T. 


\begin{tabular}{|c|c|c|c|c|}
\hline & $\begin{array}{l}\text { Group B } \\
(n=553)\end{array}$ & $\begin{array}{l}\text { Group } T \\
(n=553)\end{array}$ & $\begin{array}{l}P \\
\text { values }\end{array}$ & $\begin{array}{l}\text { Bonferroni } \\
\text { correction }\end{array}$ \\
\hline Inadequate analgesia(rest pain) & $68(12.3 \%)$ & $63(11.6 \%)$ & 0.723 & $>0.99$ \\
\hline Inadequate analgesia(moving pain) & $326 \rrbracket 59.1 \% \rrbracket$ & $241 \rrbracket 43.6 \% \bigotimes$ & $<0.001$ & $<0.001$ \\
\hline Extra analgesia requirement & $14(2.5 \%)$ & $4(0.7 \%)$ & 0.017 & 0.034 \\
\hline Dizziness & $9(1.6 \%)$ & $4(0.7 \%)$ & 0.163 & 0.326 \\
\hline Nausea and vomiting & $11(2.0 \%)$ & $11(2.0 \%)$ & $>0.99$ & $>0.99$ \\
\hline Off-bed activity at 2 day after cesarean delivery & $439 ه 79.4 \% \rrbracket$ & $356(64.4 \% \square$ & $<0.001$ & $<0.001$ \\
\hline $\begin{array}{l}\text { Intestinal function recovery at } 2 \text { day after cesarean } \\
\text { delivery }\end{array}$ & $410 \otimes 74.1 \% \rrbracket$ & $371(67.2 \%)$ & 0.050 & 0.100 \\
\hline Hospitalisation stay(day) & $3.8 \pm 1.5$ & $3.7 \pm 1.6$ & 0.222 & 0.444 \\
\hline Hospitalisation cost(yuan) & $13225 \pm 3455$ & $14767 \pm 3575$ & $<0.001$ & $<0.001$ \\
\hline
\end{tabular}

\section{Figures}




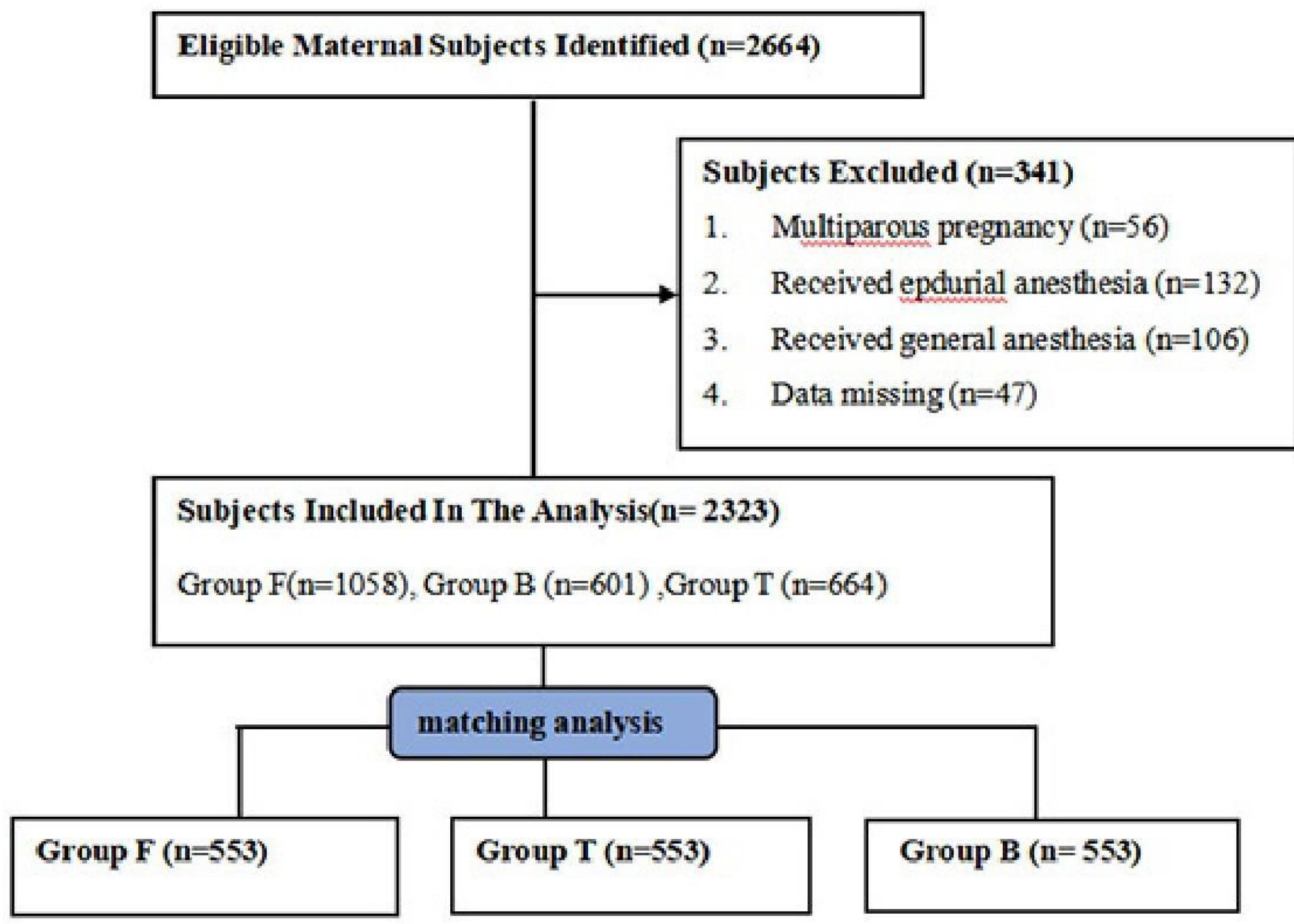

Figure 1

Flow diagram of patient inclusion. 